\title{
Communication, communication, communication
}

\section{ON YOUR MARKS, GET SET, GO! PILOTING ADVANCE CARE PLANNING EDUCATION}

10.1136/bmjspcare-2011-000053.14

S Russell', C Fowler ${ }^{1}{ }^{1}$ Hospice of St Francis, Hertfordshire, UK; ${ }^{2}$ Mount Vernon Cancer Network Education Lead, Hertfordshire, UK

In 2009, Mount Vernon Cancer Network piloted four 1 day experiential advance care planning (ACP) workshops in four locations facilitated by two educators. The training the trainer model was considered early in order to increase the availability of ACP facilitators across MVCN. Participants to the 1 day workshops were invited to attend a $1 / 2$ day 'Teaching Advance Care Planning'.

51 participants attended the workshops:

- $45 \%$ Community Matrons, District, Respiratory Specialist Nurses, Care Home Staff

- $18 \%$ palliative care education roles

- $15 \%$ hospice care 
- $12 \%$ Clinical Nurse Specialists in Palliative Care

- $6 \%$ hospice social workers

- $4 \%$ associate specialist/GP assistant roles.

The participants confidence increased significantly following attendance at the workshops: Pre Post

Confidence in explaining ACP 54\% 100\%.

What a statement of wishes and preferences is 33\% 93\%.

What an advance decision to refuse treatment is $24 \% 91 \%$.

When lasting power of attorney (welfare) is used $15 \% 87 \%$.

A 'Teaching Advance Care Planning' $1 / 2$ day interactive workshop discussed the rationale for the 1 day course, signposting to relevant resources and information about the wider evidence base for advance care planning. Participants brought to the sessions the type of sessions, target audience and timings that they planned to deliver training to. Draft lesson plans and resources were produced during the workshop for them to take away to practice. Delivery methods and interactive exercises were also discussed and offered. The education model was further developed and delivered in 2010 . 